\title{
Association Between CD133 Expression and Prognosis in Human Lung Adenocarcinoma
}

\author{
NAOKI YAMASHITA ${ }^{1,2}$, TSUNEHIRO OYAMA ${ }^{1,3}$, TETSUYA SO $^{2}$, TAKEAKI MIYATA $^{4}$, \\ TAKASHI YOSHIMATSU ${ }^{5}$, RYUJI NAKANO ${ }^{6}$, WATARU MATSUNAGA ${ }^{1}$ and AKINOBU GOTOH ${ }^{1}$ \\ ${ }^{1}$ Laboratory of Cell and Gene Therapy, Hyogo College of Medicine, Nishinomiya, Japan; \\ ${ }^{2}$ Department of Thoracic Surgery, Shinkomonji Hospital, Kitakyushu, Japan \\ ${ }^{3}$ Imamitsu Home Care Clinic, Kitakyushu, Japan; \\ ${ }^{4}$ Department of Thoracic Surgery, Shinkuki General Hospital, Kuki, Japan; \\ ${ }^{5}$ Department of Thoracic Surgery, Fukuoka-Wajiro Hospital, Fukuoka, Japan; \\ ${ }^{6}$ Department of Pathology, Fukuoka-Wajiro Hospital, Fukuoka, Japan
}

\begin{abstract}
Background/Aim: CD133 is a promising candidate marker for cancer stem cells. However, clinical studies on CD133 expression in human lung adenocarcinoma have not yet been conducted. We hypothesized that CD133 expression in lung adenocarcinoma is a poor prognostic factor. Patients and Methods: CD133 expression in lung adenocarcinoma was examined clinicopathologically. Then, clinicopathological parameters and patient prognosis were investigated. Moreover, CD133 expression was examined via immunohistochemical staining, and the relationship between CD133 expression and clinicopathological parameters was explored. Results: Approximately 48.0\% (49/102) of patients had CD133-positive cells. Based on a subgroup analysis, the CD133-positive group with pStage I+II disease had a significantly worse disease-free interval than the CD133negative group $(p<0.05)$. Conclusion: CD133 expression may be a poor prognostic factor in lung adenocarcinoma.
\end{abstract}

Cancer accounts for approximately $30 \%$ of all causes of mortality, and it is considered a leading cause of death. Moreover, the incidence of cancer-related death is increasing in the aging society (1). In particular, lung cancer is one of the most common cancers with poor prognosis worldwide, and the 5-year lung-cancer survival rate is $<15 \%$ (2). This

This article is freely accessible online.

Correspondence to: Naoki Yamashita, Institute for Advanced Medical Sciences, Hyogo College of Medicine, Laboratory of Cell and Gene Therapy, 1-1, Mukogawa-cho, Nishinomiya-City, Hyogo 663-8501, Japan. Tel: +81 798456808, Fax: +81 798456806, e-mail: naoooook1988@gmail.com

Key Words: Lung adenocarcinoma, CD133, cancer stem cell. finding may be attributed to metastasis, drug resistance to therapy and lack of target-based drugs (3).

In recent years, the concept of cancer stem cells (CSCs) in the pathophysiology of cancer has attracted attention (4). Cancer tissues were previously considered to be a population of tumor cells that have acquired different properties by random growth, such as development and maintenance of malignancy and resistance to treatment. Later, they were found to be controlled by stem cells that form the basis of cancer tissues $(5,6)$. In 1997, Bonnet et al. demonstrated that cells expressing cell surface markers such as CD34 and CD38 are CSCs in acute myeloid leukemia. Moreover, they also demonstrated that CSCs is at the top in terms of hierarchy (7). In 2003, Al-Hajj et al. revealed that CD44+CD24-/low cells were CSCs in breast cancer, and CSCs in solid cancers have been a topic of interest (8). To date, the presence of CSCs has been reported in colorectal, breast, ovarian, bladder cancers and other types of malignancies (9-12). In addition, CSCs can satisfy the following properties $(6,13)$ : [1] a minor population of cancer cells with tumorigenicity, [2] the ability to produce cell populations with low or lacking tumorigenicity and [3] selfrenewal ability. Hence, they can replicate themselves, thereby producing identical cells, and differentiate into several types of cells. While they maintain cells identical to themselves by self-renewal in cancer tissues, CSCs can produce most surrounding cancer cells by differentiation. Moreover, CSCs can cause recurrence and metastasis through resistance to anticancer drugs and radiation therapy (14). Hence, the biological characteristics of cancer stem cells can be a new therapeutic target.

The CD133 antigen, also called prominin 1, is a 5transmembrane domain glycoprotein (15). Its function is currently unknown. However, it may be a specific cell surface marker of CSC in several malignancies, including 

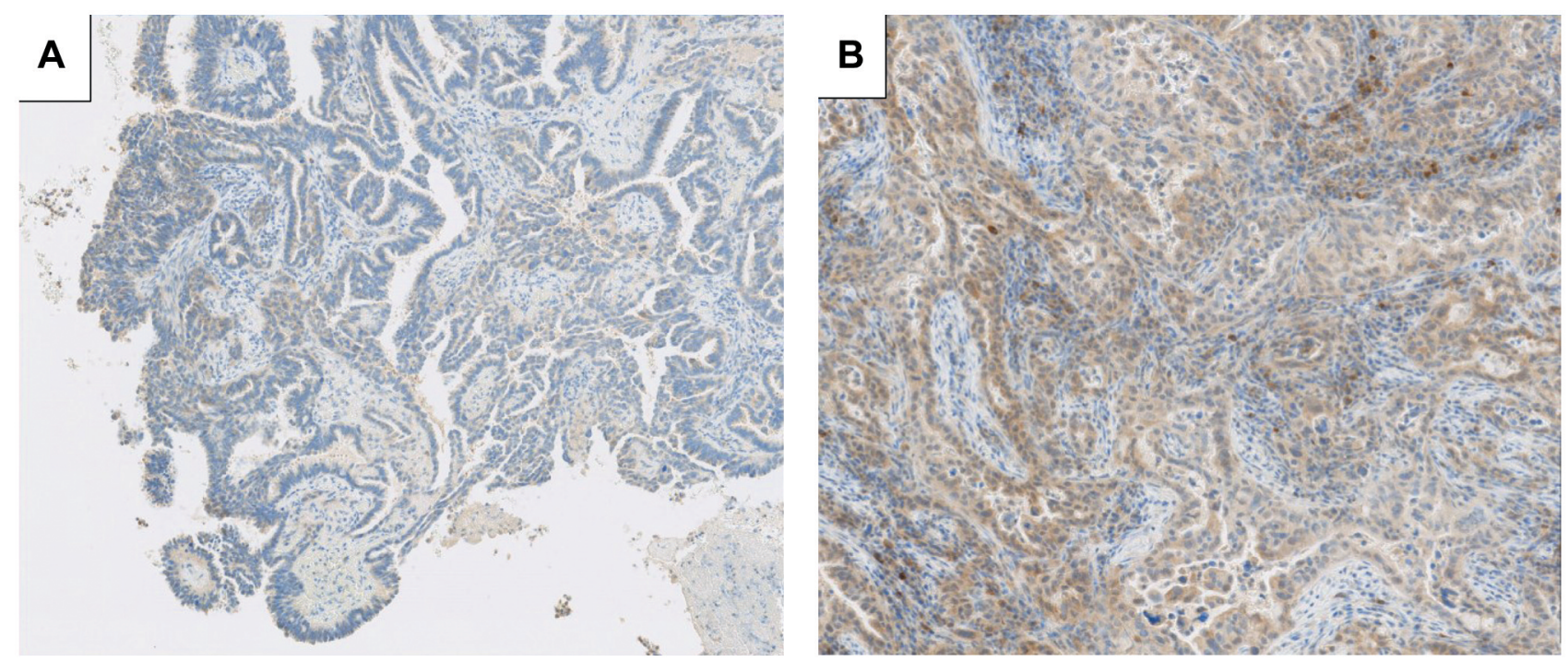

Figure 1. The CD133 expression score was defined as the proportion of cells with strong expression levels on membranous staining. The percentage of positive cells was graded as 0\%-100\%. A) 5\%, negative. B) 100\%, positive.

those of the central nervous system and colon, breast, prostate and ovarian cancers $(8,16-19)$. CD133 is a promising candidate marker for CSCs because tumor cells expressing CD133 have high tumorigenicity and resistance to differentiation and radiation therapies $(20,21)$. Currently, some studies have demonstrated that CD133 expression in a subpopulation of lung-cancer cells should identify them as a CSC. However, this remains controversial (22). Therefore, we investigated the relationship between CD133 expression and clinical parameters in lung adenocarcinoma.

\section{Patients and Methods}

In total, 186 patients with lung adenocarcinoma underwent complete or partial resection from 2010 to 2018 at Shinkomonji Hospital. Pathological specimens were used to assess clinicopathological parameters. The mean age at the time of surgery was 72 (range $=43-89$ years). None of the patients received chemotherapy or radiation before surgery. Tumor staging was performed in accordance with the 8th edition of TNM staging for lung-cancer guidelines. The clinicopathological parameters included age, sex, surgical procedure, smoking history, pathological stage and tumor marker levels (CEA: Carcinoembryonic antigen, SLX: Sialyl Lewis X-i antigen and CYFRA: Cytokeratin 19 fragment). Sectioning of lung adenocarcinoma was performed for immunohistochemical staining for CD133 using a standard immunoperoxidase technique, as described previously (23). CD133 staining was performed on $4-\mu \mathrm{m}$-thick paraffin sections using a mouse monoclonal antibody (anti-CD133; Millipore Inc., Temecula, CA, USA) at 1:200 dilution. The CD133 expression score was defined as the proportion of cells with strong membranous staining in tumor sections. The percentage of positive cells was graded as $0 \%-100 \%$ (Figure 1 ). CD133 positivity was defined as staining of more than $20 \%$ of the tumor cells (negative: $\leq 20 \%$, positive: $>20 \%$ ). The survival curves were evaluated using the Kaplan-Meier method. $p$-Values $\leq 0.05$ were considered statistically significant. This study received ethical approval for human subjects from Hospital Research Ethics Committee. Informed consent was obtained from each patient.

\section{Results}

Of 186 patients with lung adenocarcinoma, 102 (54.8\%) were eligible for this study and were examined. Approximately $48.0 \%$ (49/102) of patients had CD133-positive cells, with a cut-off value of $20 \%$. Next, the relationship between the tumor markers and prognosis was examined, and the results are presented in Table I. The prognosis for overall survival (OS) was poor in the elderly ( $\geq 75$ years) $(p<0.05)$, but there was no difference in gender. Smokers had a significantly worse OS and disease-free interval (DFI) than non-smokers $(p<0.05)$. As to the surgical procedure, others (partial resection, etc.) $(\mathrm{n}=14$, $13.7 \%)$ had a worse prognosis than lobectomy $(n=88,86.3 \%)$. There were $79(77.4 \%)$ patients with pathological stage I+II and $23(22.5 \%)$ patients with stage III+IV cancer. Patients with advanced-stage lung adenocarcinoma had a worse prognosis than patients with early-stage disease $(p<0.05)$ (Figure 2). Next, in terms of tumor markers, patients with high serum CEA levels ( $>5 \mathrm{ng} / \mathrm{ml}$ ) had significantly worse OS and DFI compared to those with normal CEA levels. Patients with high serum SLX levels (>38 U/ml) had significantly worse OS than those with normal SLX levels. However, OS and DFI were not significantly different between patients with high (>3.5 ng/ml) serum CYFRA levels and those with normal 
Table I. CD133 expression and its relationship with clinical parameters.

\begin{tabular}{|c|c|c|c|c|c|c|c|}
\hline \multirow[b]{2}{*}{ Parameters } & \multicolumn{3}{|c|}{ Total } & \multicolumn{4}{|c|}{ CD133 expression } \\
\hline & Number $(\%)$ & $p$-Value (OS) & $p$-Value (DFI) & Positive (\%) & Negative & $p$-Value (OS) & $p$-Value (DFI) \\
\hline Total & 102 & & & $49(48.0)$ & 53 & & \\
\hline \multicolumn{8}{|l|}{ Age } \\
\hline$<75$ years & $63(64.7)$ & 0.0002 & 0.5962 & $30(47.6)$ & 33 & 0.6623 & 0.1537 \\
\hline$\geq 75$ years & $39(35.3)$ & & & $19(48.7)$ & 20 & & \\
\hline \multicolumn{8}{|l|}{ Gender } \\
\hline Female & $45(44.1)$ & 0.3959 & 0.9152 & $24(53.3)$ & 21 & 0.5495 & 0.1026 \\
\hline Male & $57(55.9)$ & & & $25(43.8)$ & 32 & & \\
\hline \multicolumn{8}{|l|}{ Smoking hystoly } \\
\hline Never and former & $69(67.6)$ & 0.0487 & 0.0215 & $32(46.3)$ & 37 & 0.9824 & 0.2148 \\
\hline Current & $33(32.3)$ & & & $17(51.5)$ & 16 & & \\
\hline \multicolumn{8}{|l|}{ Surgical procedure } \\
\hline Lobectomy & $88(86.3)$ & 0.0011 & 0.6481 & $40(45.5)$ & 48 & 0.9340 & 0.1164 \\
\hline Others & $14(13.7)$ & & & $9(64.2)$ & 5 & & \\
\hline \multicolumn{8}{|l|}{ Pathological stage } \\
\hline $\mathrm{I}+\mathrm{II}$ & $79(77.4)$ & $<0.0001$ & 0.0009 & $36(45.6)$ & 43 & 0.8271 & 0.2449 \\
\hline $\mathrm{III}+\mathrm{IV}$ & $23(22.5)$ & & & $13(56.5)$ & 10 & & \\
\hline \multicolumn{8}{|l|}{ Serum CEA } \\
\hline Negative & $63(61.8)$ & 0.0102 & $<0.0001$ & $28(44.4)$ & 35 & 0.6994 & 0.4430 \\
\hline Positive & $39(38.2)$ & & & $21(53.8)$ & 18 & & \\
\hline \multicolumn{8}{|l|}{ Serum SLX } \\
\hline Negative & $87(85.3)$ & 0.0093 & 0.1687 & $38(43.7)$ & 49 & - & 0.1975 \\
\hline Positive & $15(14.7)$ & & & $11(73.3)$ & 4 & & \\
\hline \multicolumn{8}{|l|}{ Serum CYFRA } \\
\hline Negative & $70(68.6 \%)$ & 0.1039 & 0.1089 & $31(44.3)$ & 39 & 0.9693 & 0.1100 \\
\hline Positive & $32(31.4 \%)$ & & & $18(56.3)$ & 14 & & \\
\hline
\end{tabular}

Significant $p$-Values are shown in bold.

serum CYFRA levels. From a CSC viewpoint, there was no significant difference in the CD133 levels and other clinical parameters. Nevertheless, the CD133-positive group had worse OS than the CD133-negative group (Figure 3). In particular, the CD133-positive group with pStage I+II disease (43/79) had a significantly worse DFI $(p<0.05)$ (Figure 4$)$.

\section{Discussion}

Lung cancer is a preventable cancer, but once it starts, it is one of the cancers with the poorest prognosis. Lung cancer mortality shows a slight downward trend that is mainly due to smoking control and improved early detection and treatment. However, the 5-year survival rate is low because lung cancer has few symptoms, many metastases and recurrences, and a low rate of curative treatment. As in this case, elderly and smokers had a significantly poorer prognosis (Table I). Currently, only a small proportion of lung cancer is detected early, and more effective methods are needed to reduce lung cancer morbidity and mortality. Understanding the etiology of lung cancer, as we did in our study of CSC, may allow the development of novel therapies.
CSCs are commonly associated with resistance to anticancer drugs. However, this is easy to understand if the presence of CSCs is considered (24-26). These cells have similar properties to those of tissue stem cells and a slow division rate, and they can remain in the quiescent phase (G0 phase) for a long period. However, radiation/chemotherapy targets cancer cells with a high division rate. Therefore, CSCs are resistant to chemotherapy because of their characteristics. To date, CSCs often express multidrugresistant genes, which can lead to metastasis and recurrence.

The biological function of CD133 remains unknown. After isolating CD133-positive cells from human glioma, Singh et al. transplanted 100 CD133 cells in NOD/SCID mice. Then, tumor development was observed (10). In contrast, mice transplanted with CD133-negative cells did not develop tumors even after transplanting $\geq 105$ cells. Furthermore, Ricci-Vitiani et al. revealed that in colorectal cancer, the CD133-positive cells account for approximately $2.5 \%$ of tumor cells in a densely populated region. This is associated with the development of a tumor similar to the primary lesion in immunodeficient mice (27). O'Brien et al. reported that CSCs were concentrated in the CD133-positive fraction 


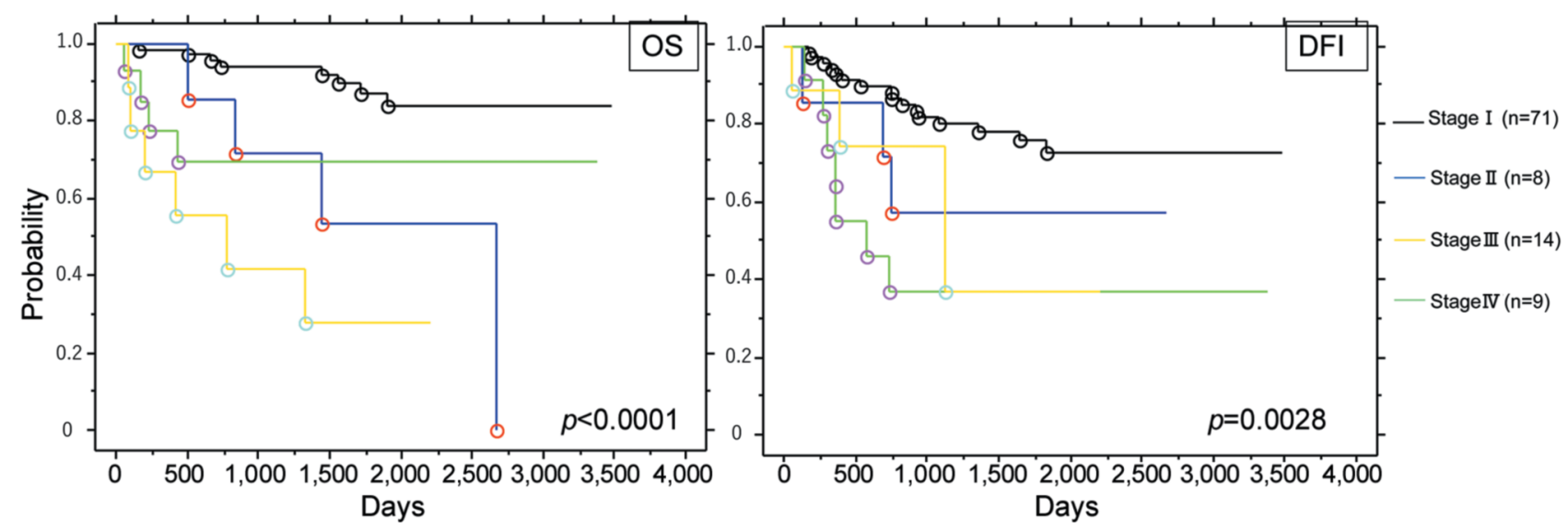

Figure 2. The Kaplan-Meier analysis of overall survival (OS) and disease-free interval (DFI) in patients with lung adenocarcinoma. In total, 102 patients presented with lung adenocarcinoma. Among them, 71, 8, 14 and 9 had stage I, II, III and IV disease, respectively.

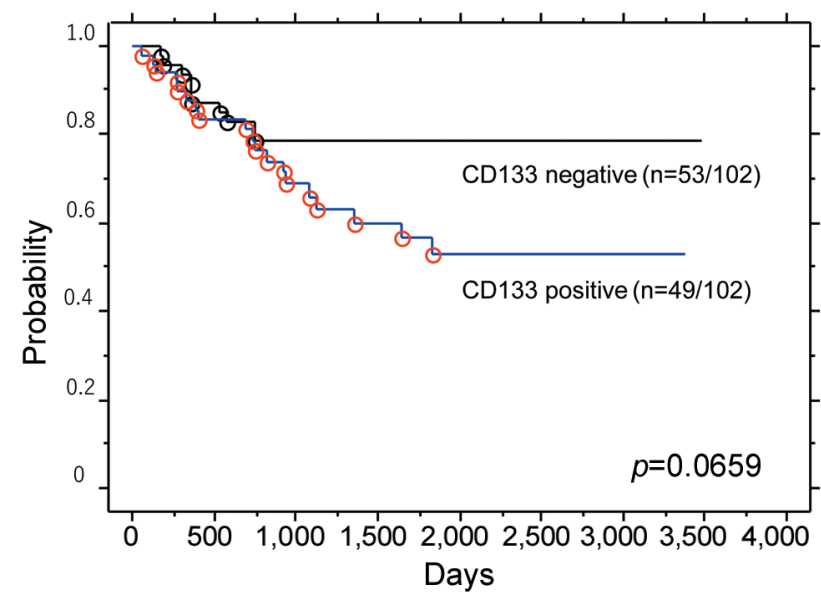

Figure 3. Kaplan-Meier analysis of DFI in patients with lung adenocarcinoma according to CD133 expression.

in colorectal cancer (17). However, the potential prognostic value of CD133 when used as a marker of CSCs in solid tumors remains controversial (28-30). Our study revealed that immunohistological CD133 expression was correlated with the pathological stage of human adenocarcinoma, particularly with stage I+II disease. In the study of Engeng et al., only Asian patients with non-small cell lung cancer who had high CD133 expression had a short OS (22). These results suggest that investigating CD133 cells by isolating samples from Asian patients with early-stage lung adenocarcinoma may be a good therapeutic strategy. For example, drug therapy is used as postoperative adjuvant therapy instead of surgery alone for lung adenocarcinoma

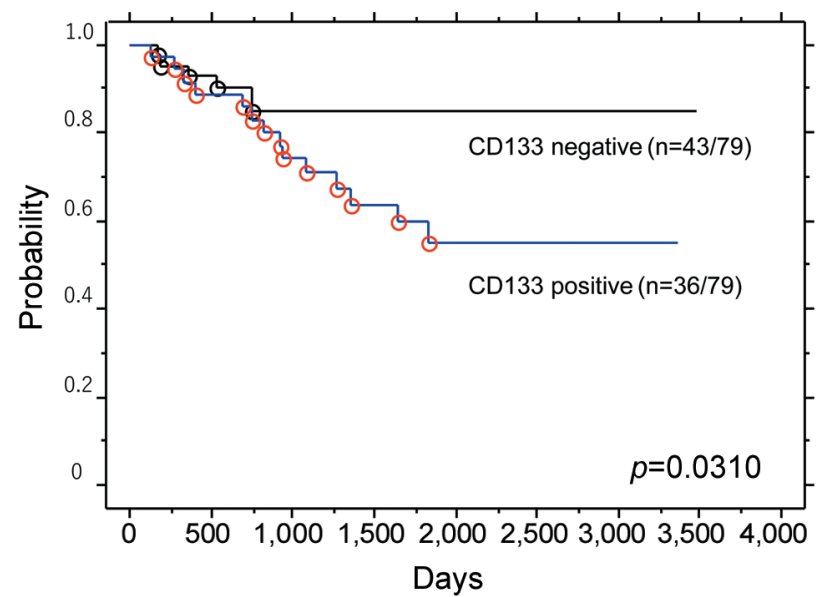

Figure 4. Survival curves of DFI according to CD133 expression in pStage I+II disease.

expressing CD133. However, the mechanism by which CD133-expressing cells are associated with recurrence and metastasis remains unclear. Hence, further research should be conducted.

These findings indicate that targeting CSCs can facilitate cancer treatment. Therefore, studies on important CSC markers should be carried out, and novel therapeutic strategies should be developed.

In future studies, we will investigate the relationship between CD133 and other CSC markers. Moreover, unfavorable prognostic factors will be assessed and used for the multidisciplinary treatment of early-stage lung adenocarcinoma. 


\section{Conflicts of Interest}

The Authors declare that there are no conflicts of interest in relation to this study.

\section{Authors' Contributions}

Tsunehiro Oyama designed the study, data analysis and acquisition of funding. Tetsuya So analysis data. Takeaki Miyata, Takashi Yoshimatsu, Wataru Matsunaga, Akinobu Gotoh revised it critically for important intellectual content.

\section{Acknowledgements}

The Authors would like to thank the Department of Pathology at Shinkomonji Hospital and the Laboratory of Cell and Gene Therapy, Hyogo College of Medicine, for providing specimens and for technical support.

\section{References}

1 Siegel RL, Miller KD and Jemal A: Cancer statistics, 2016. CA Cancer J Clin 66: 87-108, 2016. PMID: 26742998. DOI: $10.3322 /$ caac. 21332

2 Gao W, Lin L, Lu X and Shu Y: Circulating microRNAs: possible prediction biomarkers for personalized therapy of nonsmall-cell lung carcinoma. Clin Lung Cancer 12(1): 14-17, 2011. PMID: 21273174. DOI: 10.3816/CLC.2011.n.001

3 Minna JD, Roth JA and Gazdar AF: Focus on lung cancer. Cancer Cell 1(1): 49-52, 2002. PMID: 12086887. DOI: 10.1016/s1535-6108(02)00027-2

4 Bruce WR and Van Der Gaag H: A Quantitative assay for the number of murine lymphoma cells capable of proliferation in vivo. Nature 199: 79-80, 1963. PMID: 14047954. DOI: 10.1038/199079a0

5 Hamburger AW and Salmon SE: Primary bioassay of human tumor stem cells. Science 197(4302): 461-463, 1977. PMID: 560061. DOI: 10.1126/science.560061

6 Reya T, Morrison SJ, Clarke MF and Weissmann IL: Stem cells, cancer, and cancer stem cells. Nature 414: 105-111, 2001. PMID: 11689955. DOI: $10.1038 / 35102167$

7 Bonnet D and Dick JE: Human acute myeloid leukemia is organized as a hierarchy that originates from a primitive hematopoietic cell. Nat Med 3(6859): 730-737, 1997. PMID: 9212098. DOI: $10.1038 / \mathrm{nm} 0797-730$

8 Al-Hajj M, Wicha MS, Benito-Hernandez A, Morrison SJ and Clarke MF: Prospective identification of tumorigenic breast cancer cells. Proc Natl Acad Sci 100(7): 3983-3988, 2003. PMID: 12629218. DOI: 10.1073/pnas.0530291100

9 Jonker DJ, Nott L, Yoshino T, Gill S, Shapiro J, Ohtsu A, Zalcberg J, Vickers MM, Wei AC, Gao Y, Tebbutt NC, Markman B, Price T, Esaki T, Koski S, Hitron M, Li W, Li Y, Magoski NM, Li CJ, Simens J, Tu D and O'Callaghan CJ: Napabucasin versus placebo in refractory advanced colorectal cancer: a randomised phase 3 trial. Lancet Gastro Hepatol 3(4): 263-270, 2018. PMID: 29397354. DOI: 10.1016/S2468-1253(18)30009-8

10 Nilendu P, Kumar A, Pal JK and Sharma NK: Breast cancer stem cells as last soldiers eluding therapeutic burn: A hard nut to crack. Int J Cancer 142(1): 7-17, 2018. PMID: 28722143. DOI: 10.1002/ijc.30898
11 Mihanfar A, Attari JA, Mohebbi I, Majidinia M, Kaviani M, Yousefi M and Yousefi B: Ovarian cancer stem cell: A potential therapeutic target for overcoming multidrug resistance. J Cell Physiol 234(4): 3238-3253, 2019. PMID: 30317560. DOI: $10.1002 / j \mathrm{jcp} .26768$

12 Li Y, Lin K, Yang Z, Han N, Quan X, Guo X and Li C: Bladder cancer stem cells: Clonal origin and therapeutic perspectives. Oncotarget 8(39): 66668-66679, 2017. PMID: 29029546. DOI: 10.18632 /oncotarget.19112

13 Fidler IJ and Hart IR: Biological diversity in metastatic neoplasms: origins and implications. Science 217(4564): 9981003, 1982. PMID: 7112116. DOI: 10.1126/science.7112116

14 Fearon ER, Hamilton SR and Vogelstein B: Clonal analysis of human colorectal tumors. Science 238(4824): 193-197, 1987. PMID: 2889267. DOI: 10.1126/science. 2889267

15 Yin AH, Miraglia S, Zanjani ED, Almeida-Porada G, Ogawa M, Leary AG, Olweus J, Kearney J and Buck DW: AC133, a novel marker for human hematopoietic stem and progenitor cells. Blood 90(12): 5002-5012, 1997. PMID: 9389720.

16 Singh SK, Clarke ID, Terasaki M, Bonn V, Hawkins C, Squire $\mathrm{J}$ and Dirks P: Identification of a cancer stem cell in human brain tumors. Cancer Res 63(18): 5821-5828, 2003. PMID: 14522905.

17 O'Brien CA, Pollett A, Gallinger S and Dick J: A human colon cancer cell capable of initiating tumour growth in immunodeficient mice. Nature 445(7123): 106-110, 2007. PMID: 17122772. DOI: 10.1038/nature05372

18 Collins AT, Berry PA, Hyde C, Stower MJ and Maitland NJ: Prospective identification of tumorigenic prostate cancer stem cells. Cancer Res 65(23): 10946-10951, 2005. PMID: 16322242. DOI: $10.1158 / 0008-5472$

19 Bapat SA, Mali AM, Koppikar CB and Kurrey NK: Stem and progenitor-like cells contribute to the aggressive behavior of human epithelial ovarian cancer. Cancer Res 65(8): 3025-3029, 2005. PMID: 15833827 . DOI: $10.1158 / 0008-5472$

20 Angelastro JM and Lame MW: Overexpression of CD133 promotes drug resistance in C6 glioma cells. Mol Cancer Res 8(8): 1105-1115, 2010. PMID: 20663862. DOI: 10.1158/15417786

21 Piao LS, Hur W, Kim TK, Hong SW, Kim SW, Choi JE, Sung PS, Song MJ, Lee BC, Hwang D and Yoon SK: CD133(+) liver cancer stem cells modulate radioresistance in human hepatocellular carcinoma. Cancer Lett 312: 129-137, 2012. PMID: 22079466. DOI: 10.1016/j.canlet.2011.10.012

22 Chen E, Zeng Z, Bai B, Zhu J and Song Z: The prognostic value of CSCs biomarker CD133 in NSCLC meta-analysis. Oncotarget 7(35): 56526-56539, 2016. PMID: 27489355. DOI: 10.18632/ oncotarget.10964

23 Miyata T, Oyama T, Yoshimatsu T, Higa H, Kawano D, Sekimura A, Yamashita N, So $\mathrm{T}$ and Gotoh A: The clinical significance of cancer stem cell markers ALDH1A1 and CD133 in lung adenocarcinoma. Anticancer Res 37(5): 2541-2547, 2017. PMID: 28476825. DOI: 10.21873/anticanres.11597

24 Kummermehr J and Trott KR: Tumor stem cells. Stem Cells 12: 363-399, 1997. DOI: 10.1016/0167-8140(94)90002-7

25 Williams SD, Birch R, Einhorn LH, Irwin L, Greco FA and Loehrer PJ: Treatment of disseminated germ cell tumors with cisplatin, bleomycin, and either vinblastine or etoposide. N Engl J Med 316(23): 1435-1439, 1987. PMID: 2437455. DOI: 10.1056/NEJM198706043162302 
26 Lippman ME: High-dose chemotherapy plus autologous bone marrow transplantation for metastatic breast cancer. $\mathrm{N}$ Engl J Med 342(15): 1119-1120, 2000. PMID: 10760313. DOI: 10.1056/NEJM200004133421508

27 Ricci-Vitiani L, Lombardi DG, Pilozzi E, Biffoni M, Todaro M, Peschle C and Maria RD: Identification and expansion of human coloncancer-initiating cells. Nature 445(23): 111-115, 2007. PMID: 17122771. DOI: 10.1038/nature05384

28 Qiu ZX, Zhao S, Mo XM and Li WM: Overexpression of PROM1 (CD133) confers poor prognosis in non-small cell lung cancer. Int J Clin Exp Pathol 8(6): 6589, 2015. PMID: 26261540 .

29 Sullivan JP, Spinola M, Dodge M, Raso MG, Behrens C, Gao B, Schuster K, Shao C, Larsen JE, Sullivan LA, Honorio S, Xie Y, Scaglioni PP, DiMaio JM, Gazdar AF, Shay JW, Wistuba II and Minna JD: Aldehyde dehydrogenase activity selects for lung adenocarcinoma stem cells dependent on notch signaling. Cancer Res 70(23): 9937-9948, 2010. PMID: 21118965. DOI: 10.1158/ 0008-5472.CAN-10-0881
30 Zhao Y, Peng J, Zhang E, Jiang N, Li J, Zhang Q, Zhang X and Niu Y: CD133 expression may be useful as a prognostic indicator in colorectal cancer, a tool for optimizing therapy and supportive evidence for the cancer stem cell hypothesis: a meta-analysis. Oncotarget 7(9): 10023-10036, 2016. PMID: 26840260. DOI: 10.18632 /oncotarget. 7054

Received December 21, 2020

Revised January 8, 2021

Accepted January 13, 2021 